Check for updates

Cite this: Mater. Adv., 2020, 1,3476

Received 19th August 2020, Accepted 11th November 2020

DOI: $10.1039 / \mathrm{d} 0 \mathrm{ma00621a}$

rsc.li/materials-advances

\section{DES-N-doped oxygenated carbon dot colloidal solutions for light harvesting and bio-imaging applications $\dagger$}

\author{
Krishnaiah Damarla, (D) ab Sanjay Mehra, ${ }^{a b}$ Tejwant Singh Kang, (D) ${ }^{c}$ Sonam Yadav, ${ }^{a b}$ \\ Avinash Mishra ${ }^{a b}$ and Arvind Kumar iD *ab
}

\begin{abstract}
A novel colloidal system comprising choline oleate in deep eutectic solvent (DES: choline chlorideethylene glycol) is developed and utilized for in situ generation and stabilization of nanosized ( 1 to $3 \mathrm{~nm}$ ) $\mathrm{N}$-doped oxygenated, crystalline CDs via dissolution of gelatin. Self-assembly of choline oleate in DES has been characterized using surface tension, DLS and 2D NMR NOESY methods. The stability of colloidal CDs was examined using FTIR and Raman spectroscopy. TEM, HR-TEM, and PXRD techniques have been used to characterize CDs. Optical properties have been investigated using UV, fluorescence and time-resolved photoluminescence ( $\operatorname{TrPL}$ ) spectroscopy. Colloidal CDs possess bright blue to red luminescence and short fluorescence lifetime with exceptionally high quantum yield (ca. 82\%), and exhibited excellent biocompatibility as bioimaging agents towards labeling of bacterial cells (both Gram positive and Gram negative), thus indicating a potential benign system for disease detection, drug delivery and light harvesting applications.
\end{abstract}

Deep eutectic solvents (DESs) are transparent liquids composed of two or three components, which when mixed in an appropriate ratio form a eutectic with a melting point much lower than that of the individual components, and such behavior has been ascribed to the generation of intermolecular hydrogen bonds (H-bonds). ${ }^{1-3}$ A large number of HBAs have been exploited in combination with HBDs to have DESs with desired properties; however, the most commonly used HBA is choline chloride. ${ }^{4}$ Easy preparation of DESs with high purity, low cost, stability towards water, easy biodegradability, and pharmaceutically acceptable toxicity ${ }^{4-11}$ has made them versatile solvents for several applications, be it catalysis, extraction, biomass dissolution and processing, enhanced oil recovery, enzyme activity, extraction processes or drug delivery and materials synthesis. ${ }^{12-16}$

Apart from several advantages, ${ }^{4-11}$ DESs have some common properties with ionic liquids, such as a high thermal and chemical stability, and support self-assembly of amphiphilic

\footnotetext{
${ }^{a}$ CSIR-Central Salt and Marine Chemicals Research Institute, G. B. Marg,

Bhavnagar-364002, Gujarat, India. E-mail: arvind@csmcri.res.in, mailme_arvind@yahoo.com; Fax: +0278-2567562/2566970; Tel: $+0278-2567760$, extn. 7460

${ }^{b}$ Academy of Scientific and Innovative Research (AcSIR), Ghaziabad 201002, India

${ }^{c}$ Department of Chemistry, UGC-centre for Advance Studies - II,

Guru Nanak Dev University, Amritsar, 143005, India

$\dagger$ Electronic supplementary information (ESI) available: Materials characterization, surface tension plots, calculations of $\mathrm{QE}$, comparative $\mathrm{QE}$ and fluorescence images are provided. See DOI: 10.1039/d0ma00621a
}

molecules; therefore, the investigation of colloidal systems involving DESs has recently experienced a major upsurge. ${ }^{17-23}$ In a further development, an IL in DES colloidal formulation was constructed by Tan et al. wherein aggregation of 1-alkyl-3methylimidazolium chloride with different alkyl chain lengths in a deep eutectic solvent (DES, composed of choline chloride and glycerol) was achieved for the first time. ${ }^{24}$ Herein, we have constructed an even greener colloidal formulation comprising a bio-based IL in DES, and demonstrated its practical utility for in situ generation and stabilization of photoluminescent CDs and their application as bio-labelling and bio-imaging agents.

Compared to luminescent semiconductor quantum dots, which have known toxicity, ${ }^{25}$ photoluminescent carbon dots have attracted growing interest in biological labeling, bioimaging, drug delivery and optoelectronic device applications due to biocompatibility and low toxicity. ${ }^{26-39}$ In recent years, exciting work has been done on the synthesis of these benign materials through various routes, and references to these are nicely compiled in a recent article by Baragau et al. ${ }^{26}$ Many of these routes have severe limitations in terms of tedious synthesis process, harsh reaction conditions, requirement of surface passivation reagents, expensive starting materials and low quantum yields, and developing an efficient method still remains a challange. ${ }^{40-42}$ In this regard, continuous efforts are being made by several researchers to tune the intrinsic properties of CDs via chemical doping with heteroatoms in order to improve the quantum efficiency. ${ }^{40-46}$ 
DESs have the ability to donate and accept protons and electrons, which confers DESs the ability to interact with biomass components via establishing a H-bonding network for enhanced dissolution. In fact, DESs have been reported as good solvents and extraction agents for the extraction/dissolution of biomass/biopolymers, ${ }^{47,48}$ as well as self-assembly media for amphiphilic molecules. ${ }^{17-23}$ The ability of DESs to dissolve biomass and support self-assembly media prompted us to create a colloidal system for establishing a new and sustainable methodology for preparation of carbon dots (CDs). Herein we have developed a new simple and greener route to prepare $\mathrm{N}$-doped CDs-choline oleate ([Cho][Ola]) in a choline chlorideethylene glycol hybrid system by direct dissolution of "gelatin" a model protein as a single precursor (a rich source of carbon and nitrogen) in a colloidal solution.

Initially, we synthesized choline oleate ([Cho][Ola]) by mixing equimolar amounts of choline bicarbonate and oleic acid in toluene with continuous stirring at $100{ }^{\circ} \mathrm{C}$ for $24 \mathrm{~h}$ under reflux conditions. The purity of [Cho][Ola] was ensured from ${ }^{1} \mathrm{H}$ NMR and LC-MS techniques (Fig. S1, ESI $\dagger$ ). Colloidal solutions were then prepared by addition of [Cho][Ola] in choline chlorideethylene glycol (1:2 mole ratio). The molecular structure of the components used in the construction of colloidal solutions is shown in Fig. 1.

Aggregation behavior of [Cho][Ola] in DES (chlorideethylene glycol) was characterized using surface tension, DLS and 2D NOESY measurements (Fig. 2a-d).

The [Cho][Ola]-DES system exhibited a minimum in the surface tension profiles (Fig. 2a), marking the saturation of the air-solution interface, and onset of aggregation of [Cho][Ola] in bulk (critical aggregation number, $c a$.). This phenomenal aggregation in DES is as good as an aqueous system (Fig. S2, ESI $\dagger$ ). Colloidal solutions were then prepared by addition of [Cho][Ola] in (c) and is likely due to cholinium ions which create the common ion as well as solvophobic effect wherein the oleate alkyl chain group spontaneously comes closer (induce aggregation). Structural organization in aggregates was envisaged from 2D NMR NOESY correlation spectra (Fig. 2c and d). The NOEs originate due to interactions between protons. NOE cross peaks (3.8 $\mathrm{ppm}$ and $4.7 \mathrm{ppm}$ ) correspond to interaction between

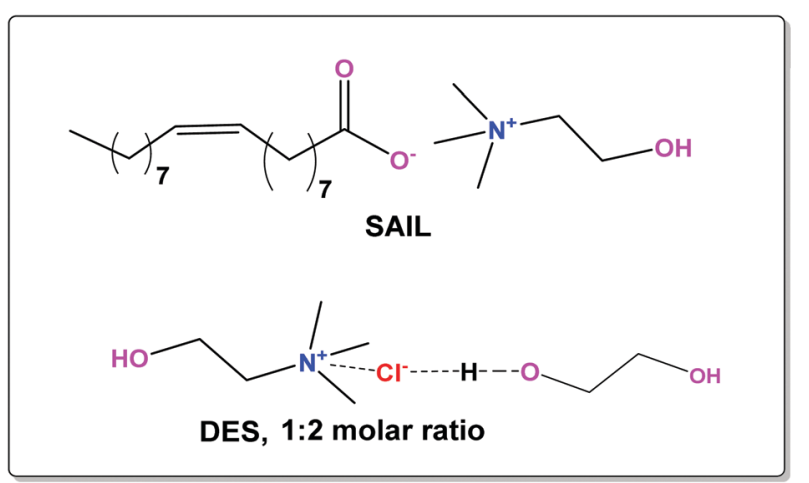

Fig. 1 Molecular structure of surface active ionic liquid (SAIL, [Cho][Ola]) and deep eutectic solvent (DES, choline chloride-ethylene glycol).
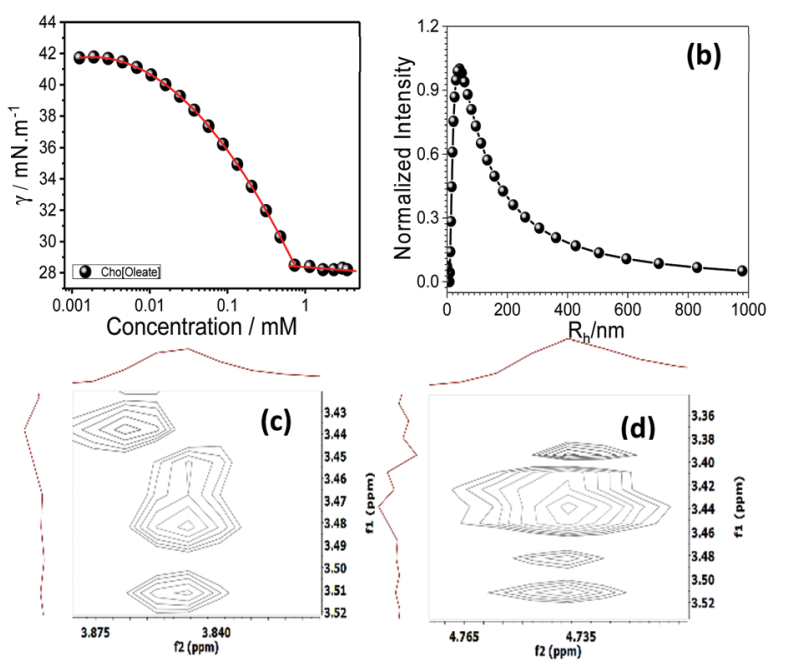

Fig. 2 (a) Surface tension, (b) DLS plot of [Cho][Ola] and (c and d) 2D NMR NOESY spectra in choline chloride-ethylene glycol (1:2 mole ratio) deep eutectic solvent (DES).

surfactant choline cation (C2) with 3.44 ppm choline cation of DES indicating the dispersion of [Cho][Ola] in DES (full spectra in ESI, $\dagger$ Fig. S3). Inference also indicates that the aggregation behavior arises from the hydrophobic effect of SAIL alkyl chains.

Dynamic light scattering measurements performed on solutions of [Cho][Ola] in DES established the presence of aggregates, and the average hydrodynamic radius $\left(R_{\mathrm{h}}\right)$ was found to be $42 \pm 20 \mathrm{~nm}$. The large size of aggregates in DES is in accordance with the earlier observations of aggregation of amphiphilic molecules in ionic liquid medium. ${ }^{49}$ The large aggregate size is due to clustering of smaller micellar structures which are loosely arranged in DES medium. In ionic medium such as DES, ions exist as positively or negatively charged ion clusters, instead of separate single ions, and makes an electrical double layer surrounding the micellar surface thereby keeping them apart through electrostatic interactions. ${ }^{50}$

[Cho][Ola]-DES colloidal solution was used to generate $\mathrm{N}$ doped, carbon-rich, CDs by direct dissolution of gelatin (1 wt\%) for $2-4 \mathrm{~h}$ at $100{ }^{\circ} \mathrm{C}$ (Fig. 3). Here, [Cho][Ola] micelles acted as the template for the synthesis of CDs. Turning of the reaction mixture from pale yellow to brown colour indicated the formation of CDs. For further confirmation of CDs in DES based micelles, we examined the DES-CDs pure solid and colloidal solutions under FT-IR (Fig. 4a and Fig. S4a, ESI $\dagger$ ) and Raman Spectroscopy (Fig. 4b and Fig. S4b, ESI $\dagger$ ) From the FT-IR spectra, the broad and intense peak centred at $3351 \mathrm{~cm}^{-1}$ is assigned to the $-\mathrm{OH}$ bending. The stretching frequencies at $2932 \mathrm{~cm}^{-1}$ and $2340 \mathrm{~cm}^{-1}$ are attributed to $-\mathrm{C}-\mathrm{H}$ and $-\mathrm{C} \equiv \mathrm{N}$ group peaks, respectively. The bands in the range of $1653 \mathrm{~cm}^{-1}$, $1562 \mathrm{~cm}^{-1}$, and $1457 \mathrm{~cm}^{-1}$ are $-\mathrm{C}=\mathrm{O},-\mathrm{N}=\mathrm{H}$, and $-\mathrm{C}=\mathrm{C}$ stretching frequencies, respectively. The peak at $1086 \mathrm{~cm}^{-1}$ represents $-\mathrm{O}-\mathrm{H}$ bending vibrations. This implies the existence of a large number of residual hydroxyl groups at the pure CDs and at the interface of the DES-CDs composite material. The appearance of two bands in the Raman spectra in both pure CDs 


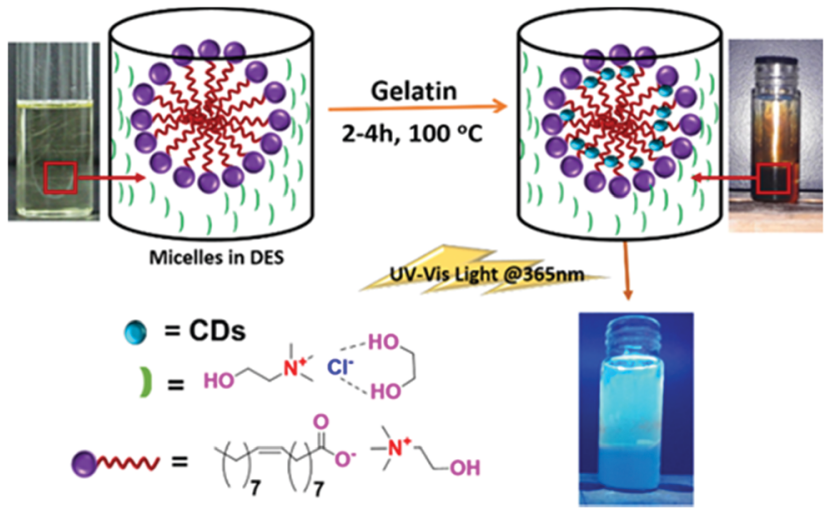

Fig. 3 Schematic representation for the preparation of colloidal luminescent $\mathrm{CDs}$ in [Cho][Ola]-DES micellar systems.
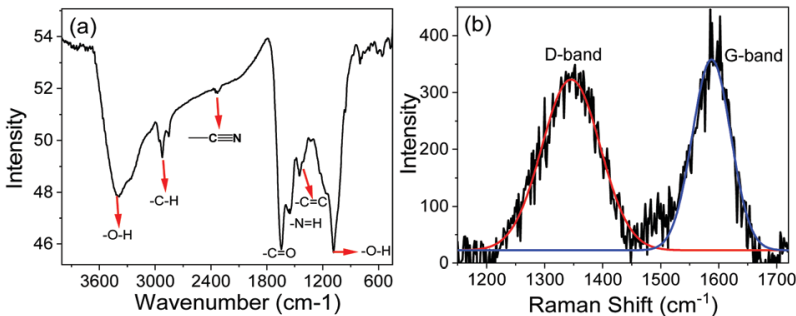

Fig. 4 (a) FT-IR spectra and (b) Raman spectra of pure N-doped CDs.

and micellar stabilized CDs (Fig. $4 \mathrm{~b}$ and Fig. S4b, ESI $\dagger$ ) i.e. at $1352 \mathrm{~cm}^{-1}$ (D band, due to breathing modes of $\mathrm{sp}^{2}$ atoms only in the rings) and $1602 \mathrm{~cm}^{-1}$ (G band, due to bond stretching of all pairs of $\mathrm{sp}^{2}$ atoms in both rings and chains) also indicates stacked nanocrystalline graphene/graphene oxide domains in the colloidal system. From these FT-IR and FT-Raman results we strongly confirm that the CDs are formed and stable in micellar form, exhibiting their fundamental properties.

The high stability of CDs in colloidal solution is likely due to strong electrostatic interactions of the carboxylate group of [Cho][Ola] with CDs at the micellar interface. Since, the hybrid system, i.e., CDs-in-micelles formed a very stable colloidal system, we devised a separation method wherein CDs could be extracted with ease. For that we added toluene in excess to the hybrid system. CDs migrated into the toluene slowly after vigorous shaking due to their hydrophobic nature. The extracted CDs were then characterized through HR-TEM and PXRD which confirmed the formation of highly crystalline ultra-small (1 to $3 \mathrm{~nm}$ ) CDs (Fig. 5a). From the HR-TEM (Fig. 5b and c), the $d$-spacing value, $0.216 \mathrm{~nm}$ corresponds to the (002) phase, which indicates the graphite lattice of the carbon dots. ${ }^{42}$ Formation of graphitic crystallinity inside the $\mathrm{CD}$ structure has been observed. Generation of $\mathrm{sp}^{2}$ bonded $\mathrm{C}-\mathrm{C}$ domains, organized into a $2 \mathrm{D}$ honeycomb lattice inside the carbon core, was revealed by the TEM broad and multiple $d$ spacing values. The lattice phase of the CDs was also confirmed by XRD diffraction $(2 \theta)$ at $22.69^{\circ}$ which corresponds to the (002) phase of the graphite lattice (Fig. $5 \mathrm{~d}$ ). $\mathrm{N}$ doped CDs when

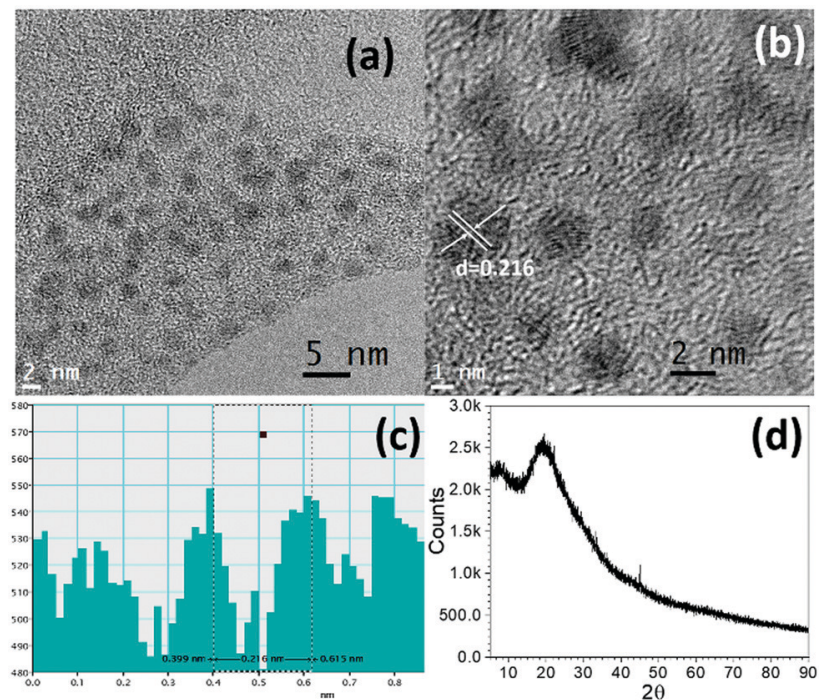

Fig. 5 Plots show (a) TEM, (b) HR-TEM, (c) $d$-spacing values obtained from HR-TEM and (d) PXRD of pure CDs.

dispersed in toluene showed intense blue light emission under UV-Visible light (365 nm) indicating passivation of the surface with oleate ions (Fig. S5, ESI $\dagger$ ). The presence of interaction of [Cho][Ola] carboxyl groups with CDs in DES offers various surface modifications for potential applications in sustainable energy conversion materials and for bioimaging purposes. Therefore, $\mathrm{N}$ doped CDs-[Cho][Ola]-DES colloidal solutions were further examined for their optical properties.

UV-Vis spectroscopy and emission spectra strongly corroborated the formation of CDs. ${ }^{42,45}$ The broad absorbance band (300 to $415 \mathrm{~nm}$ ) and slight broad adsorption peak from $\sim 400$ to $580 \mathrm{~nm}$ originate from both $\mathrm{n}-\pi^{*}$ and $\pi-\pi^{*}$ charge-transfer transitions and indicated the $\mathrm{N}$-doped oxygen-functionalized graphitic CDs (Fig. 6a).

Using the maximum absorbance $\left(\lambda_{\text {ex }}\right)$ value, we recorded the emission spectra at different excitation values such as spectra at $300,360,380,390,400,430,450,460,480$ and $500 \mathrm{~nm}$ and which showed emission of the light (bluish to red) at 416, 456, 458, 462, 471, 514, 527, 544 and 556 nm (Fig. 6b and Fig. S6, ESI $\dagger$ ) indicating formation and stabilization of CDs in DESbased micelles wherein different emissions originated from different luminescence centres. ${ }^{51}$ Blue emission normally originates from the surface defects and the green emission arises from molecular states with distinct energy levels. The CIE colour coordinates $[(0.22,0.21),(0.23,0.28),(0.24,0.29),(0.24$, $0.31),(0.25,33),(0.31,0.46),(0.35,0.52),(0.37,0.54),(0.41,0.56)$ and $(0.45,0.54)]$ calculated from the different emission spectra indicated the blue to red emission from the CDs-DES hybrid colloidal system at different excitation values (Fig. 6c).

Time-resolved photoluminescence (TrPL) was employed to understand the excited-state lifetime of colloidal CDs emitting blue light by monitoring the decay profiles at $456 \mathrm{~nm}$ (Fig. 6d, IRF spectra provided as Fig. S7, ESI $\dagger$ ). The emission of blue light under ultra violet rays is likely due to surface-state emission, and attributed to the presence of surface energy traps that 

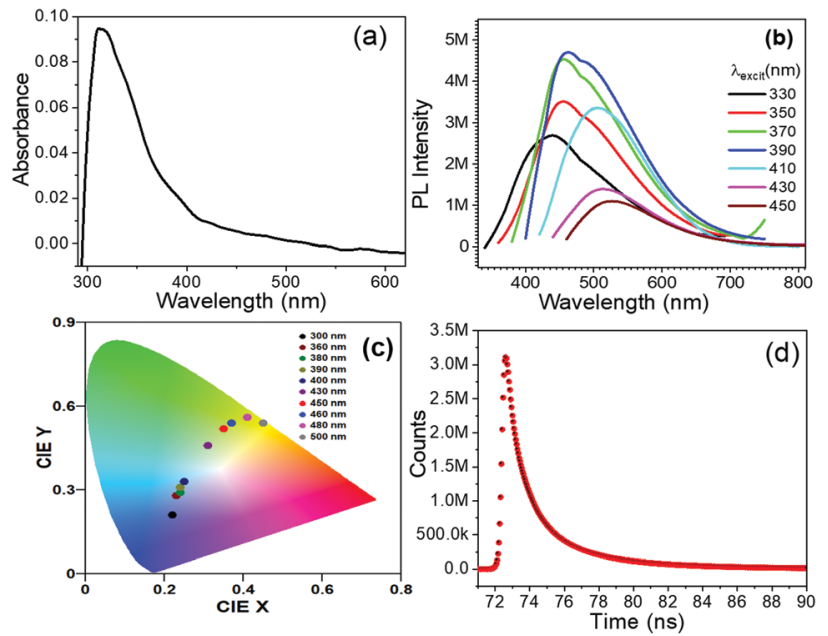

Fig. 6 (a) UV-Vis spectra, (b) fluorescence spectra, (c) chromaticity diagram indicating bluish emission, and (d) time resolved photo luminescence spectra of $\mathrm{N}$ doped CDs-[Cho][Ola]-DES colloidal solution.

become emissive upon stabilization as a result of the surface passivation in micelles. ${ }^{52}$ The decay dynamics of the ensembles of colloidal CDs usually exhibit multiexponential dynamics and the kinetics follows the equation, $A+B_{1} \mathrm{e}_{\tau_{1}}^{-t}+B_{2} \mathrm{e}_{\tau_{2}}^{-t}+B_{3} \mathrm{e}_{\tau_{3}}^{-t}$. This is a tri-exponential decay function, where $\tau_{1}, \tau_{2}$ and $\tau_{3}$ represent the shorter lifetime and longer lifetime, respectively, and $B_{1}, B_{2}$ and $B_{3}$ are the amplitude of the components at $t=0$. The shorter lifetime is the intrinsic recombination and the longer time is due to radiative recombination of electrons and holes. The fitting data of the micelles-CDs hybrid system show $\tau_{1}, \tau_{2}$ and $\tau_{3}$ equal to 3.07, 7.34 and 18.02 ns respectively. Therefore, the major surface-related emission is due to the radiative recombination of charge carriers involving surface states.

Quantum efficiency (QE) of the surface-state emission of the micelles-CD hybrid system was determined by a relative method with the area under its curve with the area under the band-edge peak emission (ESI $\dagger$ ). The obtained QE is remarkably very high $c a$. $82 \%$ and is much larger than previously reported for light emitting CDs or doped CDs (Fig. 7 and Table S1, ESI $\dagger$ ).

Very high QE is likely due to passivation of quenching defects on the surface and suppression of non-radiative surface trap sites existing on the surface of the CDs by the oleate ions in a manner similar to that accounted for by a dramatic increase in fluorescence QE of CdSe nanocrystals (8\% to $45 \%) .{ }^{53}$ Confinement of CDs with a large number of DES ions in micelles which creates the polarization effects at the interface between CDs and surrounding ions is also contributing towards increase of $\mathrm{QE}$. The previous reports on antimicrobial activity of DES (choline chloride-ethylene glycol) and SAIL, [Cho][Ola] checked against Gram positive and Gram negative bacteria and the EC50 values come under practically harmless. ${ }^{54,55}$ CDs synthesized from biomass show nontoxic effects against bacteria and fungi in antimicrobial studies. ${ }^{56}$ In this study four different bacteria, Escherichia coli, Vibrio owensii, Bacillus cereus,

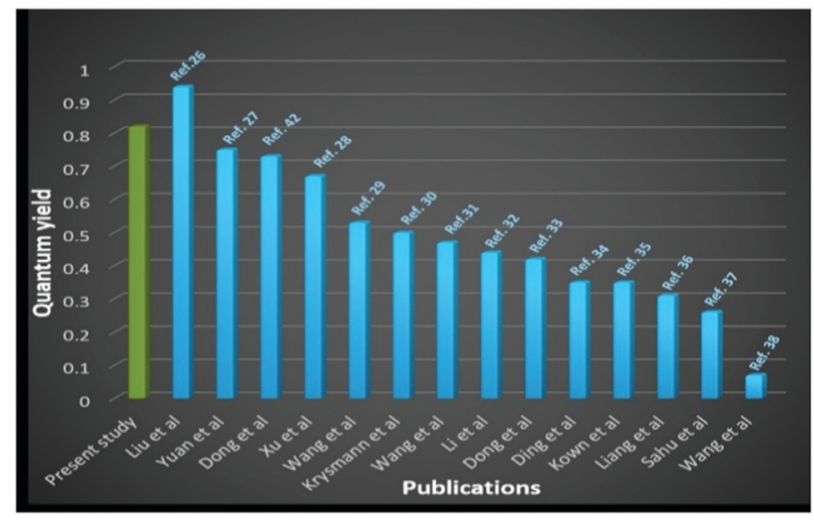

Fig. 7 Comparison of quantum yield of CDs synthesized by different research groups with the present work (ref. = reference).

and Vibrio alginolyticus of $\mathrm{OD}_{600} 0.6$ were grown in Luria broth supplemented with colloidal-CDs $(4: 1)$ for $16 \mathrm{~h}$ at $30{ }^{\circ} \mathrm{C}$ with $180 \mathrm{rpm}$. Bacterial cells were pelleted by centrifugation (5000 rpm for $4 \mathrm{~min}$ at $4{ }^{\circ} \mathrm{C}$ ), washed with phosphate-buffered saline (PBS; $5000 \mathrm{rpm}, 4 \mathrm{~min}$ ) and suspended in PBS. Bacterial cells were observed under an epifluorescence microscope at a wavelength $\lambda_{\max } 575 \mathrm{~nm}$ and normal light. Commonly, colloidal CDs interact with bacteria through electrostatic interaction, ${ }^{57}$ and some colloidal CDs may lead to ROS generation in bacterial cells, whereas other cannot. ${ }^{58}$ ROS inhibition activity was studied with all four bacterial strains treated with different dilutions of DES-N-CDs containing colloidal solution. No or negligible ROS inhibitory activity was observed up to $\frac{1}{4}$ dilution, whereas about 50-60\% ROS inhibition was estimated with higher concentration of colloidal CDs. Therefore, it may be concluded that low concentration of CDs does not generate ROS in bacterial cells, while higher dose leads to ROS generation. A very good fluorescence indicated that the CDs were easily internalized in bacterial cells (Fig. 8 and Fig. S8-S11, ESI $\dagger$ ). The results also confirmed that due to the greener nature of all the components, the colloidal solutions of $\mathrm{N}$-doped CDs-choline oleate ([Cho][Ola]) in choline chloride-ethylene glycol can be directly applied in growth media up to very high concentrations, and CDs have the capability to be retained by bacterial cells.

In conclusion, the ability of deep eutectic solvents to dissolve biopolymers and to support self-assembly of amphiphilic molecules has been exploited to develop a novel green colloidal formulation (choline oleate ([Cho][Ola]) in choline chlorideethylene glycol system) wherein $\mathrm{N}$-doped carbon dots have been generated and stabilized in micelles by direct dissolution of biopolymer gelatin. The colloidal CDs exhibited varying light emission (bluish to red) depending upon the excitation wavelength with a very high quantum yield ( $c a$. 82\%). The CDs also showed a very good biocompatibility with different bacteria for cell labelling. Such a system holds promise as a potential material for light harvesting and bioimaging applications suitable for single molecule resolution due to very small size ( 1 to $3 \mathrm{~nm}$ ) of CDs. In future, there is a brighter prospect for 

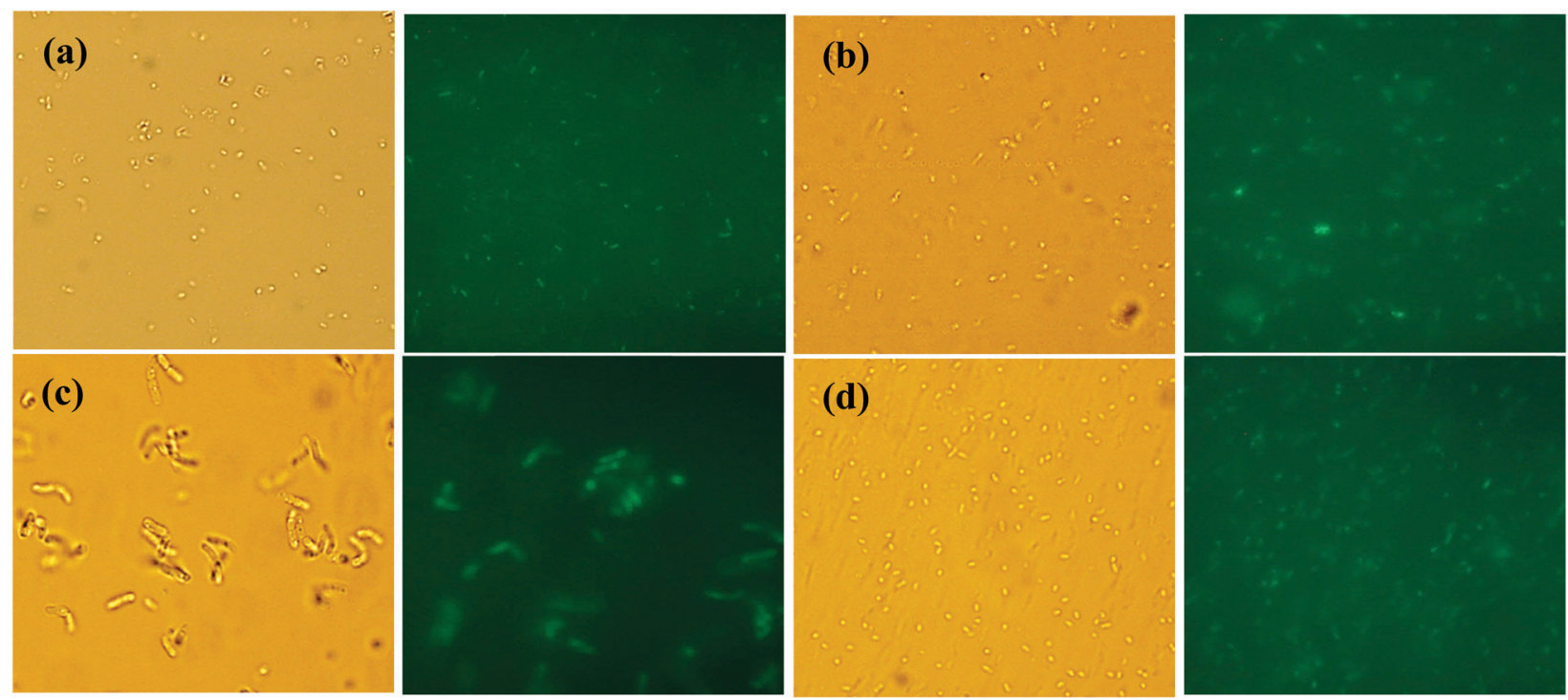

Fig. 8 Fluorescence microscopic images of different types of bacteria under normal light and through a green filter: (a) Escherichia coli, (b) Vibrio owensii, (c) Bacillus cereus, and (d) Vibrio alginolyticus of $\mathrm{OD}_{600}$ 0.6, labelled with the N-doped carbon dots.

developing more such tailor-made colloidal CDs as an inexpensive, stable, and biocompatible marker with tuneable light emission and quantum efficiency by choice of biofriendly ionic liquids or deep eutectic solvents, amphiphilic molecules and biopolymers.

\section{Materials and methods}

\section{Materials}

Oleic acid $(>99 \%)$ was obtained from TCI India, choline chloride $(\geq 99 \%)$, and choline bicarbonate $(\geq 80 \%)$ and gelatin ( $>98 \%)$ type A (300 Bloom, IEP $=9.0)$ were purchased from Sigma-Aldrich. Ethylene glycol, hexane, ethyl acetate and toluene were purchased from SRL India and SD fine chemicals Ltd., India, respectively. Milli-Q water was used wherever required. All the chemicals were of AR grade and were used as received.

\section{Methods}

Synthesis of SAIL. Equimolar amounts of choline bicarbonate and respective oleic acid are dissolved in toluene and stirred at $100{ }^{\circ} \mathrm{C}$ for $24 \mathrm{~h}$ under reflux conditions and the progress of the reaction was monitored using TLC. The product was obtained by concentrating the reaction mixture (removal of toluene). After washing with ethyl acetate and hexane the product was dried under vacuum for several hours to remove the moisture present and was stored in a desiccator. The purity of the [Cho][Ola] SAIL was ensured using ${ }^{1} \mathrm{H}$ NMR and LC-MS techniques (Fig. S1, ESI†).

FTIR, FT-Raman and FT-NMR measurements. FT-IR measurements were carried out at $25{ }^{\circ} \mathrm{C}$ using a PerkinElmer FT-IR spectrometer using $\mathrm{BaF}_{2}$ windows and a Teflon spacer. The optical path length was $0.02 \mathrm{~mm}$. For each spectrum, at least 20 scans were made with a resolution of $0.5 \mathrm{~cm}^{-1}$. The Raman shift was characterized using LabRAM HR Evolutions (Horiba Jobin Yvon) Raman Spectroscopy.

NMR measurements. ${ }^{1} \mathrm{H} \& 2 \mathrm{D}$ NOESY NMR experiments were performed on a JEOL $600 \mathrm{MHz}$ NMR spectrometer.

Surface tension. The surface tension measurements were performed in DES and water systems using SAIL to measure the surface tension using an Attention Sigma 700 Biolin scientific instrument with automated titrants employing the Du Noüy ring method. The solutions (SAIL in water/DES) were prepared at 10 times higher concentration than that of $\mathrm{cmc}$ and left for at least $15 \mathrm{~min}$. Then, the solutions were titrated against the pure desired solvent which was taken in a standard vessel having diameter $70 \mathrm{~mm}$. The data was noted with an accuracy within $\pm 0.1 \mathrm{mN} \mathrm{m}^{-1}$.

Dynamic light scattering (DLS). DLS measurements of solutions with known viscosity and refractive indices were carried out in a quartz cuvette of $1 \mathrm{~cm}$ path length, at $298.15 \mathrm{~K}$ on Spectro Size ${ }^{\mathrm{TM}} 300$ (NaBiTec, Germany) light scattering apparatus with a He-Ne laser at a wavelength of 660-670 nm, and power $4 \mathrm{~mW}$ as a source at an angle of $90^{\circ}$. The data evaluation of the DLS measurements was performed with the inbuilt CONTIN algorithm. The temperature of the measurements was controlled with an inbuilt thermoelectric peltier device with an accuracy of $\pm 0.1 \mathrm{~K}$.

Ultra violet-visible spectroscopy. The UV-Vis spectra of the synthesized materials in micelles have been measured using a UV 3600 Shimadzu UV-vis-NIR spectrophotometer at $298.15 \mathrm{~K}$. In a typical experiment, the colloidal solutions were taken in a quartz cuvette of $1 \mathrm{~cm}$ path length with different concentrations.

Fluorescence spectroscopy. Fluorescence measurements were performed using an Edinburgh Instruments Xe900 $(\mu \mathrm{F} 920 \mathrm{H})$ spectrofluorometer using a quartz cuvette of path length $1 \mathrm{~cm}$. The intrinsic fluorescence of CDs, in colloidal formulations in DES was measured at their respective 
excitation/emission wavelength. The maximal values of fluorescence are the average of three measurements.

Time resolved photoluminescence spectroscopy (TrPL). Fluorescence decay profiles were measured using a timecorrelated single-photon counting spectrometer i.e., Edinburgh instruments OB 920 fluorescence spectrophotometer using a pulsed diode laser (laser - EPLED-375 nm; emission: $456 \mathrm{~nm}$ ) as an excitation source. Fluorescence lifetimes were measured by plotting fluorescence decay curves as a function of time $(t)$.

Transmission electron microscopy (TEM). The images were taken using a JEOL JEM-2100 electron microscope at a working voltage of $80 \mathrm{kV}$. Samples were prepared by putting a drop of sample solution on the carbon/lacy-coated copper grid (300 mesh) and prior to analysis it was dried for 24 hours in a vacuum desiccator.

Powder X-ray diffraction (PXRD). X-Ray measurements were performed using an XRD instrument, Philips X'pert MPD system with CuK $\alpha$ radiation $(\lambda=1.54056 \AA)$.

Bio-imaging studies. Four different bacteria, Escherichia coli, Bacillus cereus, Vibrio owensii, and Vibrio alginolyticus of $\mathrm{OD}_{600}$ 0.6 were grown in Luria broth supplemented with ILS CDs containing colloidal solutions $(4: 1)$ for $16 \mathrm{~h}$ at $30{ }^{\circ} \mathrm{C}$ with $180 \mathrm{rpm}$. The next day, bacterial cells were pelleted by centrifugation (5000 rpm for $4 \mathrm{~min}$ at $4{ }^{\circ} \mathrm{C}$ ), washed in with phosphate-buffered saline (PBS; $5000 \mathrm{rpm}, 4 \mathrm{~min}$ ) and suspended in PBS. Bacterial cells were observed under an epifluorescence microscope (Axio Imager, Carl Zeiss AG, Germany) and documented.

\section{Funding sources}

Department of science and technology (DST), India and Council of Scientific and Industrial Research (CSIR), India.

\section{Conflicts of interest}

The authors declare no competing financial interests.

\section{Acknowledgements}

CSIR-CSMCRI - 095/2019. Department of Science and Technology (DST), Government of India (No. EMR/2016/004747). K. D. is thankful to CSIR for providing financial help as SRF. Analytical and environment division \& central instrumentation facility of CSIR-CSMCRI is also acknowledged for helping in the sample characterizations.

\section{References}

1 P. Wasserscheid and W. Keim, Angew. Chem., Int. Ed., 2000, 39, 3772-3789.

2 A. P. Abbott, D. Boothby, G. Capper, D. L. Davies and R. K. Rasheed, J. Am. Chem. Soc., 2004, 126, 9142-9147.

3 A. P. Abbott, G. Capper, D. L. Davies, H. L. Munro, R. K. Rasheed and V. Tambyrajah, Chem. Commun., 2001, 2010-2011.
4 A. P. Abbott, G. Capper, D. L. Davies and R. Rasheed, Inorg. Chem., 2004, 43, 3447-3452.

5 Y. Dai, G.-J. Witkamp, R. Verpoorte and Y. H. Choi, Anal. Chem., 2013, 85, 6272-6278.

6 W. Bi, M. Tian and K. H. Row, J. Chromatogr. A, 2013, 1285, 22-30.

7 Q. Zhang, K. D. O. Vigier, S. Royer and F. Jerome, Chem. Soc. Rev., 2012, 41, 7108-7146.

8 Y. Yu, X. Lu, Q. Zhou, K. Dong, H. Yao and S. Zhang, Chem. Eur. J., 2008, 14, 11174-11182.

9 K. D. Weaver, H. J. Kim, J. Sun, D. R. MacFarlane and G. D. Elliott, Green Chem., 2010, 12, 507-513.

10 F. Ilgen, D. Ott, D. Kralisch, C. Reil, A. Palmberger and B. König, Green Chem., 2009, 11, 1948-1954.

11 D. Reinhardt, F. Ilgen, D. Kralisch, B. König and G. Kreisel, Green Chem., 2008, 10, 1170-1181.

12 M. Zdanowicz and T. Spychaj, Polimery, 2011, 56, 861-864.

13 A. Mohsenzadeh, Y. Al-Wahaibi, A. Jibril, R. Al-Hajri and S. Shuwa, J. Pet. Sci. Eng., 2015, 130, 6-15.

14 E. Durand, J. Lecomte and P. Villeneuve, Eur. J. Lipid Sci. Technol., 2013, 115, 379-385.

15 Y. Dai, G.-J. Witkamp, R. Verpoorte and Y. H. Choi, Food Chem., 2015, 187, 14-19.

16 S. Tuntarawongsa and T. Phaechamud, Polymeric Eutectic Drug Delivery System, J. Met., Mater. Miner., 2012, 22, 27-32.

17 T. L. Greaves and C. J. Drummond, Chem. Soc. Rev., 2008, 37, 1709-1726.

18 O. Zech and W. Kunz, Soft Matter, 2011, 7, 5507-5513.

19 A. Sanchez-Fernandez, K. J. Edler, T. Arnold, R. K. Heenan, L. Porcar, N. J. Terrill, A. E. Terry and A. J. Jackson, Phys. Chem. Chem. Phys., 2016, 18, 14063-14073.

20 A. Sanchez-Fernandez, O. S. Hammond, A. J. Jackson, T. Arnold, J. Doutch and K. J. Edler, Langmuir, 2017, 33, 14304-14314.

21 A. Sanchez-Fernandez, G. L. Moody, L. C. Murfin, T. Arnold, A. J. Jackson, S. M. King, S. E. Lewis and K. J. Edler, Soft Matter, 2018, 14, 5525-5536.

22 M. Pal, R. Rai, A. Yadav, R. Khanna, G. A. Baker and S. Pandey, Langmuir, 2014, 30, 13191-13198.

23 Komal, G. Singh, G. Singh and T. S. Kang, ACS Omega, 2018, 3, 13387-13398.

24 X. Tan, J. Zhang, T. Luo, X. Sang, C. Liu, B. Zhang, L. Peng, W. Li and B. Han, Soft Matter, 2016, 12, 5297-5303.

25 A. P. Alivisatos, Science, 1996, 271, 933-937.

26 I.-A. Baragau, N. P. Power, D. J. Morgan, T. Heil, R. A. Lobo, C. S. Roberts, M.-M. Titirici, S. Dunn and S. Kellici, J. Mater. Chem. A, 2020, 8, 3270-3279.

27 H. Liu, Z. Li, Y. Sun, X. Geng, Y. Hu, H. Meng, J. Ge and L. Qu, Sci. Rep., 2018, 8, 1-8.

28 F. Yuan, Z. Wang, X. Li, Y. Li, Z. Tan, L. Fan and S. Yang, Adv. Mater., 2017, 29, 1604436.

29 Q. Liang, W. Ma, Y. Shi, Z. Li and X. Yang, Carbon, 2013, 60, 421-428.

30 Q. Xu, P. Pu, J. Zhao, C. Dong, C. Gao, Y. Chen, J. Chen, Y. Liu and H. Zhou, J. Mater. Chem. A, 2015, 3, 542-546. 
31 Z. Wang, F. Yuan, X. Li, Y. Li, H. Zhong, L. Fan and S. Yang, Adv. Mater., 2017, 29, 1702910.

32 M. J. Krysmann, A. Kelarakis, P. Dallas and E. P. Giannelis, J. Am. Chem. Soc., 2012, 134, 747-750.

33 F. Wang, Z. Xie, H. Zhang, C. Liu and Y. Zhang, Adv. Funct. Mater., 2011, 21, 1027-1031.

34 X. Li, S. Zhang, S. A. Kulinich, Y. Liu and H. Zeng, Sci. Rep., 2014, 4, 4976.

35 Y. Dong, R. Wang, H. Li, J. Shao, Y. Chi, X. Lin and G. Chen, Carbon, 2012, 50, 2810-2815.

36 H. Ding, S.-B. Yu, J.-S. Wei and H.-M. Xiong, ACS Nano, 2016, 10, 484-491.

37 W. Kwon and S.-W. Rhee, Chem. Commun., 2012, 48, 5256-5258.

38 S. Sahu, B. Behera, T. K. Maiti and S. Mohapatra, Chem. Commun., 2012, 48, 8835-8837.

39 Q. Wang, X. Huang, Y. Long, X. Wang, H. Zhang, R. Zhu, L. Liang, P. Teng and H. Zheng, Carbon, 2013, 59, 192-199.

40 H. Li, F.-Q. Shao, S.-Y. Zou, Q.-J. Yang, H. Huang, J.-J. Feng and A.-J. Wang, Microchim. Acta, 2015, 183(2), 821-826.

41 Q.-Y. Cai, J. Li, J. Ge, L. Zhang, Y.-L. Hu, Z.-H. Li and L.-B. Qu, Biosens. Bioelectron., 2015, 72, 31-36.

42 Y. Dong, H. Pang, H. Bin Yang, C. Guo, J. Shao, Y. Chi, C. M. Li and T. Yu, Angew. Chem., Int. Ed., 2013, 52, 7800-7804.

43 H. Fei, R. Ye, G. Ye, Y. Gong, Z. Peng, X. Fan, E. L. G. Samuel, P. M. Ajayan and J. M. Tour, ACS Nano, 2014, 8, 10837-10843.

44 G. Hong, S. Diao, A. L. Antaris and H. Dai, Chem. Rev., 2015, 115, 10816-10906.
45 Y. Hu, X. Geng, L. Zhang, Z. Huang, J. Ge and Z. Li, Sci. Rep., 2017, 7, 1-9.

46 J. Shangguan, J. Huang, D. He, X. He, K. Wang, R. Ye, X. Yang, T. Qing and J. Tang, Anal. Chem., 2017, 89, 7477-7484.

47 M. Zdanowicz, K. Wilpiszewska and T. Spychaj, Carbohydr. Polym., 2018, 200, 361-380.

48 Y. Chen and T. Mu, Green Energy Environ., 2019, 4, 95-115.

49 N. Li, S. Zhang, L. Zheng, B. Dong, X. Li and L. Yu, Phys. Chem. Chem. Phys., 2008, 10, 4375-4377.

50 Z. He and P. Alexandridis, Phys. Chem. Chem. Phys., 2015, 17, 18238-18261.

51 P. Zhu, K. Tan, Q. Chen, J. Xiong and L. Gao, Chem. Mater., 2019, 31, 4732-4742.

52 Y.-P. Sun, B. Zhou, Y. Lin, W. Wang, K. A. S. Fernando, P. Pathak, M. J. Meziani, B. A. Harruff, X. Wang and H. Wang, J. Am. Chem. Soc., 2006, 128, 7756-7757.

53 T. E. Rosson, S. M. Claiborne, J. R. McBride, B. S. Stratton and S. J. Rosenthal, J. Am. Chem. Soc., 2012, 134, 8006-8009.

54 M. Hayyan, M. A. Hashim, A. Hayyan, M. A. Al-Saadi, I. M. AlNashef, M. E. S. Mirghani and O. K. Saheed, Chemosphere, 2013, 90, 2193-2195.

55 M. U. H. Shah, M. Sivapragasam, M. Moniruzzaman, M. M. R. Talukder, S. B. Yusup and M. Goto, J. Mol. Liq., 2018, 266, 568-576.

56 B. S. B. Kasibabu, S. L. D'souza, S. Jha and S. K. Kailasa, J. Fluoresc., 2015, 25, 803-810.

57 F. Lin, Y.-W. Bao and F.-G. Wu, C, 2019, 5, 33.

58 W. Bing, H. Sun, Z. Yan, J. Ren and X. Qu, Small, 2016, 12, 4713-4718. 